\title{
Treatment dropout at a secondary mental health service
}

\author{
Abandono de tratamento em serviço secundário de saúde mental
}

Mário Sérgio Ribeiro, ${ }^{1}$ José Cândido Caldeira Xavier Júnior, ${ }^{2}$ Tiago Rodrigues Mascarenhas, ${ }^{2}$ Priscila Matthiesen Silva, ${ }^{2}$ Eveline Maria de Melo Vieira, ${ }^{2}$ Luiz Cláudio Ribeiro ${ }^{3}$

\begin{abstract}
Objective: To investigate mental health dropout rates in secondary care and to identify possible associations between this variable and social, demographic, psychopathologic, and health care process-related variables.

Method: This prospective, observational study included 994 patients referred to a secondary service by four primary care units and evaluated by a specialist mental health team between 2004 and 2008. The dependent variable was treatment dropout. Bivariate analyses investigated possible associations between treatment dropout and 57 independent variables.

Results: The overall dropout rate from specialist mental health treatment was relatively low ( mean $=25.6 \%$ ). Only four independent variables were associated with dropout: one socioeconomic, two psychopathological, and one health care process variable. All associations were marginally significant $(p<0.1)$.

Conclusion: Our findings suggest that family members, patients, and health care professionals are well engaged in this mental health care system based on a model of primary care. The use of this mental health model of care should be extended to other regions of our country.

Keywords: Patient dropouts, mental health, secondary health care, quality of health care.
\end{abstract}

\section{Resumo}

Objetivo: Investigar a taxa de abandono de tratamento no nível secundário de saúde mental e identificar possíveis associações entre abandono e variáveis sociais, demográficas, psicopatológicas e do processo de cuidado.

Métodos: Este estudo observacional, prospectivo, incluiu 994 pacientes referenciados a serviço secundário por quatro unidades básicas de saúde e avaliados por uma equipe especialista em saúde mental entre 2004 e 2008. A variável independente foi abandono de tratamento. Análises bivariadas investigaram possíveis associações entre abandono e 57 variáveis independentes de diferentes dimensões.

Resultados: A taxa geral de abandono de tratamento especialista foi relativamente baixa (média $=25,6 \%$ ). Apenas quatro variáveis independentes se mostraram associadas a abandono: uma sociodemográfica, duas psicopatológicas, e uma relativa ao processo de cuidado. Todas as associações foram marginalmente significativas $(p<0,1)$.

Conclusões: Os resultados sugerem bom engajamento de pacientes, familiares e profissionais nesse sistema de atenção à saúde mental focado no modelo da atenção primária. A utilização desse modelo de assistência em saúde mental deveria ser estendido a outras regiões do país.

Descritores: Abandono do tratamento, saúde mental, atenção secundária, qualidade da assistência à saúde.

\footnotetext{
${ }^{1}$ Professor, Department of Clinical Practice, Medical School, Universidade Federal de Juiz de Fora (UFJF), Juiz de Fora, MG, Brazil. ${ }^{2}$ Medical students, UFJF. ${ }^{3}$ Professor Department of Statistics, Instituto de Ciência Exatas, UFJF.

This study was presented at a seminar held by Fundação de Amparo à Pesquisa do Estado de Minas Gerais (FAPEMIG) and at 40 Seminário Mineiro de Ciência, Tecnologia e Inovação em Saúde, both in 2010.

Financial support: Fundação de Amparo à Pesquisa do estado de Minas Gerais (FAPEMIG; EDT-3322/06 - Bolsa de iniciação científica e financiamento). Grants were provided by the Department of Mental Health of the Brazilian Unified Health System Sistema Único de Saúde de Juiz de Fora (DSM/SUS-JF), by Programa

Institucional de Bolsas de Iniciação Científica (PIBIC), and by Programa de Bolsas de Iniciação Científica da Universidade Federal de Juiz de Fora (BIC-UFJF).

Submitted May 18 2011, accepted for publication Aug 10 2011. No conflicts of interest declared concerning the publication of this article.

Suggested citation: Ribeiro MS, Xavier Jr JCC, Mascarenhas TR, Silva PM, Vieira EMM, Ribeiro LC. Treatment dropout at a secondary mental health service. Trends Psychiatry Psychother. 2012;34(4):207-14.
} 


\section{Introduction}

Mental disorders cause a great deal of suffering. The care of patients with mental problems is insufficient in terms of both quantity and quality of services available. Initiatives that contribute to increase adherence rates are necessary to reduce both mental and physical impairments and related economic impacts. ${ }^{1}$

Several authors have investigated the factors associated with mental health treatment dropout in different health care systems over the past 15 years. Even though some particularities and methodological differences can be observed in the literature -limiting comparisons -, overall results are relatively consistent. Among the factors regularly evidenced as being associated with higher dropout rates in mental health treatment at both primary and secondary health care levels, the following stand out: type of service provider and/or characteristics of health care ${ }^{2-6}$; professional responsible for referring the patient ${ }^{7,8}$; time waiting for specialist treatment and difficulties scheduling appointments ${ }^{9,10}$; patients' beliefs and expectations. ${ }^{2,3,9}$

Notwithstanding, when the influence of sociodemographic and economic factors, ${ }^{2,3,5,7,8,11,12}$ clinical factors $3,5,7,9,11-13$ - especially those related with diagnosis and condition severity -, and different treatment modalities ${ }^{2}$ are analyzed, results are extremely conflicting. In fact, to date, no factors or patterns have been consistently associated with mental health treatment dropout.

The objective of this study was to assess treatment dropout rates at a secondary health care center of the Municipal Mental Health System of Juiz de Fora (Sistema Municipal de Saúde Mental de Juiz de Fora, SMSMJF) and to identify possible associations between the outcome and 57 independent variables corresponding to different dimensions, namely, sociodemographic, psychopathological, and health care process dimensions.

\section{Method}

The SMSM-JF system, implemented in 2000, comprises 11 regional mental health centers, each one covering a specific area of the municipality of Juiz de Fora, MG. The west region referral center (Centro Regional de Referência em Saúde Mental - Oeste), which will be described in the present study, holds learning and clinical practice activities of the Psychiatry and Medical Psychology Service of the University Hospital (Hospital Universitário da Universidade Federal de Juiz de Fora, HU-UFJF). At the center, professors and psychiatry residents treat patients referred by west region primary services, amalgamating two levels of health care. The health care model referred to in the present study has been described in detail elsewhere. ${ }^{14,15}$

Before starting data collection, all professionals working at the primary health care units covered by the west region referral center underwent a short training session on diagnostic hypotheses and patient referral and treatment. The teams of each health center met monthly with investigators of the Psychiatry and Medical Psychology Service at HU-UFJF to ensure continuous improvement of the health care process. According to the management protocols of the SMSMJF system, primary health centers were expected to refer only more severe patients to the secondary level of care. At the end of the initial evaluation, the team of the referral center could either send patients back to follow-up at the primary health center or further refer them to programs specifically designed to deal with specific diagnoses. ${ }^{16}$

This exploratory observational study prospectively followed the medical records of 994 patients referred to the west region referral center who attended the first appointment over four different time periods: April 1st 2004 to March 31st 2005, April 1st 2005 to March 31st 2006, April 1st 2006 to March 31st 2007, and April 1st 2007 to March 31st 2008. The start of each period was determined taking into consideration that most patients were seen by resident psychiatrists, who start training in February or March each year, and that a 30-day period would be recommended to allow residents to adapt to the health care model.

Patients with one of the following characteristics were not included: a) patients younger than 18 years at the first appointment; b) patients for whom age was not recorded on the chart; c) patients whose charts failed to inform the date of the first or last appointment; d) patients with no information available on treatment status (outcome of interest).

The main variable of the study was treatment status, which was classified into two categories: whether or not there was treatment dropout. The health care standards indicated in the management protocols of the SMSM-JF system ${ }^{16}$ recommend that patients should have their treatment status defined by the specialist team of the referral center within 60 days from the date of referral. Based on this recommendation, treatment status was assessed every year by the authors of the present study, based on medical charts, always in the month of May following each period. Treatment dropout was determined when the patient attended the first appointment at the west region referral center but missed subsequent appointments during the period assessed, until the end of May, regardless of treatment duration. Taking into 
Table 1 - Characterization of independent variables

\begin{tabular}{|c|c|c|c|c|}
\hline Group & Dimension & Indicator & Variable & Category/Combination \\
\hline \multirow{10}{*}{$\begin{array}{l}\text { Sociodemographi } \\
\text { and economic } \\
\text { profile }\end{array}$} & Biological & Sex & Gender & Male vs. Female \\
\hline & & Age & Chronological age (self-report) & Up to 42 years vs. 43 years or more \\
\hline & & Skin color & Predominant characteristic identified & White vs. Other \\
\hline & \multirow[t]{7}{*}{ Sociocultural } & Education level & $\begin{array}{l}\text { Last school grade attended } \\
\text { (self-report) }\end{array}$ & $\begin{array}{l}\text { Up to Finished elementary school } \\
\text { vs. Unfinished high school or more }\end{array}$ \\
\hline & & Marital status & Current status & $\begin{array}{l}\text { Single/divorced/widow vs. } \\
\text { Married/partnership }\end{array}$ \\
\hline & & Children & Has children & Yes vs. No \\
\hline & & Religion & $\begin{array}{l}\text { Religion (self-report)/attendance } \\
\text { to services }\end{array}$ & Catholic vs. Other \\
\hline & & Economic status & $\begin{array}{l}\text { Income from economic activity } \\
\text { (self-report) }\end{array}$ & $\begin{array}{l}\text { Up to one minimum wage vs. } \\
\text { More than one minimum wage }\end{array}$ \\
\hline & & & Economically dependent on someone else & Yes vs. No \\
\hline & & People at home & Lives alone & Yes vs. No \\
\hline \multirow[t]{11}{*}{ Clinical profile } & \multirow[t]{8}{*}{$\begin{array}{l}\text { Psychopathological } \\
\text { and interactive }\end{array}$} & \multirow[t]{8}{*}{$\begin{array}{l}\text { Psychiatric } \\
\text { examination }\end{array}$} & $\begin{array}{l}\text { Attitudes towards the examiner } \\
\text { (cooperative, suspicious, hostile, } \\
\text { defensive, seductive, shy, authoritative, } \\
\text { ambiguous, confident, actively and/or } \\
\text { passively resistant) }\end{array}$ & Yes vs. No \\
\hline & & & $\begin{array}{l}\text { Patient's ability to locate him/herself in } \\
\text { time in relation to place and his/her self, } \\
\text { immediate fixation memory, recent memory, } \\
\text { remote memory, and short-term memory }\end{array}$ & Good vs. Impaired vs. Not sure \\
\hline & & & $\begin{array}{l}\text { Attention, thought (production, course, and } \\
\text { content), consciousness, sensory perception } \\
\text { Intelligence, impulse control/frustration } \\
\text { tolerance, information reliability, insight, } \\
\text { and motivation for treatment }\end{array}$ & $\begin{array}{l}\text { No significant abnormalities vs. } \\
\text { Significant abnormalities present } \\
\text { High vs. Average vs. Low }\end{array}$ \\
\hline & & & Way how patient tends to report problems & $\begin{array}{l}\text { Adequate vs. Attenuated vs. } \\
\text { Exaggerated }\end{array}$ \\
\hline & & & Basic affective disposition & Abnormalities vs. No abnormalities \\
\hline & & & Affective stability & Stable vs. Unstable \\
\hline & & & Affective adequacy & Adequate vs. Inadequate \\
\hline & & & Affective relationship & $\begin{array}{l}\text { Vital/endogenous vs. Fantastic/ } \\
\text { imaginary vs. Real/actual vs. } \\
\text { Not sure }\end{array}$ \\
\hline & \multirow[t]{3}{*}{ Diagnostic } & \multirow[t]{3}{*}{ Psychiatric } & $\begin{array}{l}\text { Diagnostic hypothesis (according to the } \\
\text { primary health center team) }\end{array}$ & $\begin{array}{l}\text { Anxiety/neurotic disorder vs. } \\
\text { Psychotic/delusional disorder vs. } \\
\text { Affective (mood) disorder vs. } \\
\text { Psychoactive substance use } \\
\text { disorder vs. Organic mental } \\
\text { disorder vs. Personality disorder } \\
\text { vs. More than one diagnostic } \\
\text { hypothesis }\end{array}$ \\
\hline & & & $\begin{array}{l}\text { Diagnosis established at the regional } \\
\text { mental health referral center }\end{array}$ & $\begin{array}{l}\text { Organic mental disorder vs. } \\
\text { Psychoactive substance use } \\
\text { disorder vs. Psychotic/delusional } \\
\text { disorder vs. Mood disorder vs. } \\
\text { Anxiety disorder vs. Personality } \\
\text { disorder }\end{array}$ \\
\hline & & & Primary diagnosis (regrouped) & $\begin{array}{l}\text { Mild and moderate common } \\
\text { mental disorders vs. Severe } \\
\text { mental disorders vs. Psychoactive } \\
\text { substance use disorder vs. Other } \\
\text { diagnoses }\end{array}$ \\
\hline
\end{tabular}


Table 1 - Characterization of independent variables (cont.)

\begin{tabular}{|c|c|c|c|c|}
\hline Group & Dimension & Indicator & Variable & Category/Combination \\
\hline & & $\begin{array}{l}\text { Diagnostic } \\
\text { hypotheses of } \\
\text { the primary } \\
\text { health center } \\
\text { and diagnosis } \\
\text { of the secondary } \\
\text { mental health } \\
\text { service }\end{array}$ & Diagnostic agreement of patients assessed & $\begin{array}{l}\text { Diagnostic hypotheses not } \\
\text { informed by primary health } \\
\text { center vs. Diagnosis not informed } \\
\text { by the referral center vs. Neither } \\
\text { the primary health center nor the } \\
\text { referral center teams provided } \\
\text { information on diagnosis vs. } \\
\text { Diagnostic disagreement with } \\
\text { referral center vs. Diagnostic } \\
\text { agreement with referral center }\end{array}$ \\
\hline \multirow{9}{*}{$\begin{array}{l}\text { Health care } \\
\text { dynamics (health } \\
\text { care process) }\end{array}$} & \multirow{7}{*}{$\begin{array}{l}\text { Primary health } \\
\text { center/referral } \\
\text { center interface }\end{array}$} & Date of inclusion & Date of first appointment (April 1st to & $1(2004 / 2005)$ vs. $2(2005 / 2006)$ \\
\hline & & in the study & March 31st of following year) & vs. $3(2006 / 2007)$ vs. $4(2007 / 2008)$ \\
\hline & & $\begin{array}{l}\text { Referring primary } \\
\text { health center }\end{array}$ & $\begin{array}{l}\text { Primary health center responsible } \\
\text { for referring the patient }\end{array}$ & $\begin{array}{l}\text { Borboleta vs. Santos Dumont } \\
\text { vs. São Pedro vs. Teixeiras }\end{array}$ \\
\hline & & $\begin{array}{l}\text { Quality of } \\
\text { information } \\
\text { sent to the referral }\end{array}$ & $\begin{array}{l}\text { Availability of sociodemographic } \\
\text { variables on the referral form }\end{array}$ & $\begin{array}{l}\text { Not available vs. Available but } \\
\text { incomplete vs. Available and } \\
\text { complete }\end{array}$ \\
\hline & & center & $\begin{array}{l}\text { Availability of summarized medical history } \\
\text { on the referral form }\end{array}$ & Yes vs. No \\
\hline & & & $\begin{array}{l}\text { Availability of clinical variables on the } \\
\text { referral form }\end{array}$ & $\begin{array}{l}\text { Not available vs. Available but } \\
\text { incomplete vs. Available and } \\
\text { complete }\end{array}$ \\
\hline & & $\begin{array}{l}\text { Person in charge } \\
\text { of referral }\end{array}$ & Profession of person in charge of referrals & $\begin{array}{l}\text { Participation of a physician vs. } \\
\text { No participation of a physician }\end{array}$ \\
\hline & \multirow[t]{2}{*}{$\begin{array}{l}\text { Health care } \\
\text { process } \\
\text { at the referral } \\
\text { center }\end{array}$} & $\begin{array}{l}\text { Type of treatment } \\
\text { adopted }\end{array}$ & Treatment modalities initiated & $\begin{array}{l}\text { Pharmacological only vs. Other } \\
\text { therapies } \\
\text { Presence of symbolic modality vs. } \\
\text { Absence of symbolic modality }\end{array}$ \\
\hline & & \multicolumn{2}{|c|}{ Treatment duration Number of treatment days } & Up to 60 days vs. More than 60 days \\
\hline
\end{tabular}

consideration that initial appointments always took place between April of a given year and March of the following year, and considering a uniform distribution, this criteria yielded a mean time of 7 months of patient follow-up, with a maximum of 14 months. Patients classified in the treatment retention group where those who were still being treated at the secondary health care service (referral center) at the end of May following each study period, or those who were referred to special programs or sent back to the original primary health centers for follow-up during the same period.

Demographic and socioeconomic variables were assessed based on the semi-structured clinical records used in the SMSM-JF system or via combinations of original categories. Most data were collected from the referral form filled in by the primary health center team or from charts kept at the referral center. Variables were used to calculate the median of continuous variables related to the total sample of patients or to create combinations aiming at transforming variables with more than two categories into binary variables. This strategy was used for the following variables: skin color, white or other; marital status, single/divorced/widow or married/ partnership; religion, Catholic or other; education level, up to finished elementary school or unfinished high school or more; income, up to one minimum wage or more than one minimum wage (Table 1 ). A category corresponding to no data available was used in all variables in the bivariate analyses, as will be described below.

Psychopathological and interactive variables refer to the psychiatric examination; interactive variables deal with different aspects of the specialist-patient relationship (e.g. information reliability, the way how the patient reports problems, motivation for treatment, etc.) covered in the semi-structured clinical records used in the SMSM-JF system. In the psychiatric examination chart, different attitudes of patients towards the examiner (total of 12 independent variables) are described in the semi-structured chart using yes/no questions. Another 17 variables have the following answer options: a) good, impaired, not sure, or unable to assess; b) no significant abnormalities, significant abnormalities, not sure, or unable to assess; c) high, average, low, not sure, or unable to assess.

Regardless of the variable assessed, the options not sure and unable to assess were subsequently grouped and combined with cases of no data available (based on the low frequency of responses in the two former categories).

The variables professional in charge of referral, type of treatment adopted, and treatment duration at the 
secondary level were the only ones answered by the research team after analysis of patient records. Considering the health care protocols used in the SMSM-JF system, treatment duration at the secondary level was classified into two categories: up to 60 days or more than 60 days.

Type of treatment adopted was classified into the following categories: only assessment/advice, only symbolic treatment modality, only pharmacological treatment, symbolic and pharmacological treatment, or no data available. Symbolic treatment modalities were defined as any psychotherapeutic intervention offered by professionals at the referral center. ${ }^{17}$ These categories were combined into two options: a) treatment focused on a pharmacological approach, with the subcategories pharmacological treatment only, other (including all other treatment modalities or their combination), and no data available (for cases with no information on treatment); and b) treatment focused on a psychotherapeutic approach, also with three subcategories, namely, presence of symbolic modality, absence of symbolic modality, and no data available.

The quality of referral was assessed using two variables based on the availability of sociodemographic and clinical information, both categorized as not available, available but incomplete, or available and complete. A variable was also created to assess the profession of those in charge of referral: referral made by a physician or with the participation of a physician, referral made without the participation of a physician, or no data available.

The possible influence of diagnostic hypotheses indicated by the primary health center team and of the diagnoses established by the team of the referral center was assessed using a combined variable with the following categories: a) diagnostic hypothesis not informed by the primary health center; b) primary diagnosis not informed by the referral center; c) neither the diagnostic hypothesis was informed by the primary health center nor the primary diagnosis by the referral center; d) diagnostic hypothesis and diagnosis informed, but according to specialist opinion, the patient does not present a psychiatric illness or syndrome compatible with the diagnostic hypothesis informed by the primary health center; e) diagnostic hypothesis and diagnosis have been informed and are consistent. In this assessment, it was necessary to discard cases presenting with more than one diagnostic hypothesis, as well as those in which the diagnoses established at the referral center were not compatible with the six diagnostic categories available for the team of the primary health center, namely, anxiety/neurotic disorder, psychotic/delusional disorder, affective (mood) disorder, psychoactive substance use disorder, organic mental disorder, personality disorder.
Also, considering the association between severity of psychiatric disorder and dropout rate, a variable was created to combine the diagnoses established into four major groups of mental disorders, in addition to the no data available category: 1) mild and moderate common mental disorders, including anxiety disorders, mild or moderate depressive disorders or episodes; 2) severe mental disorders, including the disorders in the F20 group of the International Classification of Diseases, Tenth Revision (ICD-10) (schizophrenia and other psychotic disorders), manic episodes or bipolar disorder, severe depressive disorders or episodes; 3 ) psychoactive substance use disorder, including the diagnostic categories F10 to F19.9 of the ICD-10; and 4) other diagnoses. ${ }^{18,19}$

The 57 independent variables were first analyzed in an exploratory manner. A bivariate analysis was used to investigate possible associations between the independent variables and the outcome of interest (treatment status). In order to identify a possible influence of the unavailability of some data, this category was considered as a separate answer option for all variables where the phenomenon was observed. In order not to bias analyses based on any criteria a priori, bivariate analyses were conducted for all independent variables, using the combinations mentioned above.

Significance of the associations was assessed using the chi-square test, and marginally significant results $(p<0.1)$ would be subsequently included in a multivariate model.

The study research project was designed in agreement with the ethical principles set forth in the Declaration of Helsinki and was approved by the Research Ethics Committee of HU-UFJF and UFJF (protocol nos. 377.062.2004, 1112.158.2007, and 1412.103.2008).

\section{Results}

Of the 994 referred patients who attended the first appointment, $66.3 \%$ were female, $46.0 \%$ were either married or in a stable relationship, $63.2 \%$ had children, $54.6 \%$ reported being Catholic, $60.7 \%$ had low education levels (up to finished elementary school), $47.1 \%$ referred having a monthly income of up to one minimum wage, and $48.8 \%$ were economically dependent on someone else. The most frequent diagnosis was mood disorder $(30.8 \%)$, and the most common treatment modality was pharmacological only (66.4\%). Mean treatment dropout at the secondary level, considering all four periods analyzed, was $25.6 \%$, ranging from a minimum of $23.9 \%$ in the first period to a maximum of $28 \%$ in the third period ( $p=$ $0.774)$. The percentage of no data available varied from $4.2 \%$ (treatment modality) to $29.6 \%$ (income). 
In the bivariate analyses, four variables showed associations, although marginally significant ones, with treatment dropout; of these, the categories with the highest percentage rates of dropout were the following: treatment duration under 60 days $(p=0.000)$, income below one minimum wage $(p=0.076)$, high impulse control/frustration tolerance $(p=0.050)$, and average level of insight $(p=0.006)$ (Table 2$)$.

Table 2 - Variables associated with treatment dropout in the bivariate analysis

\begin{tabular}{lccc}
\hline & \multicolumn{2}{c}{ Treatment status (\%) } & \\
\cline { 2 - 3 } Variable/category & No dropout & Dropout & $\mathbf{p}$ \\
\hline Treatment duration & & & \\
Up to 60 days & 68.0 & 32.0 & \\
$\quad$ More than 60 days & 84.8 & 15.2 & 0.000 \\
Income & & & \\
Up to one minimum wage & 77.8 & 22.2 & \\
$\quad$ More than one minimum wage & 71.6 & 28.4 & \\
$\quad$ No data available & 71.4 & 28.6 & 0.076 \\
Impulse control/frustration tolerance & & & \\
$\quad$ High & 69.2 & 30.8 & \\
$\quad$ Average & 72.7 & 27.3 & \\
Low & 82.6 & 17.4 & \\
$\quad$ No data available & 75.7 & 24.3 & 0.050 \\
Insight & & & \\
High & 73.7 & 26.3 & \\
Average & 68.9 & 31.1 & \\
Low & 82.5 & 17.5 & \\
No data available & 77.5 & 22.5 & 0.006 \\
\hline
\end{tabular}

When excluding from the analyses patients with no data available for each of the independent variables assessed, the only difference was a marginally significant association between increased dropout rates and referral made without the participation of a physician ( $p=0.079$ vs. 0.213 when including the no data available category; data not shown).

Taking into consideration the exploratory aims of the present study, as well as the small number of variables with at least marginally significant associations with treatment dropout or no dropout, the authors decided not to perform the multivariate model.

\section{Discussion}

Studies with different designs assessing treatment dropout at specialist services have reported dropout rates ranging from 22.3 to $46 \% \cdot^{3,6,11,20} \mathrm{~A}$ number of authors has evidenced that patient adherence may be associated with the quality of referral to a specialist service. According to Matas et al., 7 the factor most frequently associated with missed appointments is the type of service responsible for referral: $32.8 \%$ of patients referred by emergency departments did not attend the specialist appointment scheduled, compared with 11.2 and $8.6 \%$ of those referred by primary and secondary health care services, respectively. Professionals and services with a more participative approach, i.e., those that involve the patient in treatment decision-making, ${ }^{5}$ or those offering a greater deal of social support, ${ }^{4}$ tend to present lower rates of dropout. In this scenario, it is important to emphasize that in the present study it was not possible to identify any association between treatment dropout and the two variables related with quality of referral and health care.

Compared with the results of Melo \& Guimarães, ${ }^{8}$ who showed high rates of treatment dropout among patients spontaneously seeking specialist mental health services in Brazil, the relatively low rate of attrition observed in the four periods analyzed in the present study point to an effective model of mental health care between the primary and secondary levels of care. It is important to emphasize that no association was observed between treatment dropout and treatment modality adopted.

Recent studies have produced conflicting results regarding the association between mental health treatment dropout and demographic and socioeconomic factors. According to Young et al., ${ }^{12}$ Edlund et al., ${ }^{2}$ Rossi et al., ${ }^{5}$ and Wang, ${ }^{20}$ younger patients have a higher chance of abandoning treatment. Rossi et al. ${ }^{5}$ and Gonzalez et al., ${ }^{3}$ in turn, suggested that married patients are less likely to drop out of treatment, whereas Young et al. ${ }^{12}$ reached the opposite conclusion. From a different standpoint, Young et al., ${ }^{12}$ Edlund et al., ${ }^{2}$ Rossi et al., ${ }^{5}$ and Wang ${ }^{20}$ did not identify associations between sex and education level of patients who dropped out of treatment. Percudani et al. ${ }^{11}$ and Melo \& Guimarães et al. ${ }^{8}$ found a positive association between male sex and treatment dropout. Finally, Rossi et al., ${ }^{5}$ Percudani et al., ${ }^{11}$ and Wang ${ }^{20}$ did not observe significant correlations between employment status and treatment attrition.

None of the variables mentioned above was associated with treatment dropout in our sample. Rather, only income showed a correlation, i.e., subjects in the lowest income category were less likely to abandon treatment. In addition to the fact that patients with mild and moderate common mental disorders were more frequently classified in the income category of more than one minimum wage ( 61.1 vs. $54.9 \%, p=0.478$; data not shown), it is possible to infer that those with a higher income were more interested in resuming work, leading to attrition as a result of the fact that treatment is offered only during working hours.

Few investigators have assessed the association between psychological and interactive characteristics and psychiatric treatment dropout. Conversely, several studies have addressed the influence of psychiatric diagnosis on this outcome. According to Melo \& Guimarães, ${ }^{8}$ the use of alcohol or drugs upon admission 
would be significantly associated with higher treatment dropout rates. The results of Percudani et al..$^{11}$ indicate that patients with neurotic or personality disorders were less likely to drop out of treatment when compared with patients with psychotic disorders. For Rossi et al. ${ }^{5}$ and Young et al., ${ }^{12}$ a diagnosis of schizophrenia would be associated with lower rates of dropout; similarly, Amaral ${ }^{21}$ concluded that non-psychotic patients showed a lower degree of adherence to outpatient services. Dobscha et al. ${ }^{13}$ concluded that patients with major depression had the highest chance of treatment dropout; for Wang, ${ }^{20}$ patients with mood and psychoactive substance use disorders are more likely to abandon treatment when compared with patients with other diagnoses.

Even though we have not observed an association between treatment dropout and diagnosis, two psychopathological and interactive variables showed marginally significant associations with attrition, suggesting that patients with more severe disorders show better adherence. This hypothesis is corroborated by the high dropout rate observed in our patients diagnosed with mild and moderate common mental disorders, of $28.4 \%$, compared with rates ranging from 21.5 to $21.6 \%$ in the other diagnostic categories (severe mental disorders, psychoactive substance use disorder, and other diagnoses, considered separately and not taking into consideration the no data available category) $(p=0.176$; data not shown). In a study assessing psychoanalytic psychotherapy dropout, Hauck et al. ${ }^{22}$ reported statistical associations between attrition and a lower level of insight and more immature defense mechanisms.

When analyzing data on the professional in charge of referral, the category without the participation of a physician was associated with higher rates of treatment dropout. One possible hypothesis for future studies would be that the participation of physicians would contribute to a better qualification of referral for patients who indeed need to be referred to specialist treatment, requiring a more regular attendance to appointments.

In our study, the variable most strongly associated with treatment dropout was treatment duration at the secondary level: patients who stayed under treatment at the secondary level of health care for over 60 days dropped out of treatment significantly less often than those being treated for up to 60 days. This result is compatible with the hypothesis that the patients who better adhere to secondary health care are precisely those more in need of specialist treatment, with their (and their families') expectations probably being more satisfactorily met.

Few studies have prospectively assessed variables associated with treatment dropout at the interface between the primary and secondary levels of care. In spite of some important limitations of the design of the present study, discussed in detail elsewhere, ${ }^{23}$ our results (including the high number of subjects) suggest that few sociodemographic, clinical, and health care process-related variables are associated with treatment dropout in bivariate analyses.

Overall, the studies reviewed presented the following types of discrepancies: a) inclusion/exclusion criteria; b) period of time investigated; and c) variables assessed. Such heterogeneity in methods has contributed toward a low level of agreement across results with regard to risk or protection factors for treatment dropout, and also limits the comparison of data.

Gonzalez et al. ${ }^{3}$ had already indicated the need to study treatment adherence in relation to individual factors, e.g., patient experiences, beliefs, knowledge, and preferences, in an attempt to improve adherence rates and thus reduce negative effects on the mental health and consequently on the physical health of the users of these services.

Considering that the investigation of treatment dropout can help identify flaws in the services provided, ${ }^{12}$ the present results seem to indicate that: a) the studied population probably had already overcome the difficulty underscored by Amaral $^{21}$ of recognizing the primary health care network as a treatment option - or at least as a first option - for the treatment of mental health problems; and $b$ ) contradicting the findings of Luchese et al. ${ }^{24}$ primary health care teams seem to be well engaged in this mental health care system and ready to develop their roles within the referral system.

\section{Conclusion}

In this study, only four of 57 variables assessed were associated with treatment dropout, and only at a marginally significant level: a) one sociodemographic variable (income); b) two psychopathological variables (impulse control/frustration tolerance and level of insight); and c) one related to the health care process (treatment duration at the secondary health care service). Our results point to the possibility of improving the quality of health care by refining the referral process from the first to the second level of care. They also suggest a good engagement of professionals, patients, and family members in the mental health care services provided through a system based on the primary care model. Future studies should assess the effectiveness of this mental health care model in comparison with the dominant model in our country, i.e., demand-centered and focusing on specialist services. 


\section{References}

1. Organização Mundial da Saúde. Relatório mundial da saúde 2001. Saúde mental: nova concepção, nova esperança. Lisboa: OMS; 2001. http://www.who.int/whr/2001/en/ whr01_po.pdf. Accessed 2006 Jun 05.

2. Edlund MJ, Wang PS, Berglund PA, Katz SJ, Lin E, Kessler RC. Dropping out of mental health treatment: patterns and predictors among epidemiological survey respondents in the United States and Ontario. Am J Psychiatry. 2002;159:845-51.

3. Gonzalez J, Williams Jr JW, Noël PH, Lee S. Adherence to mental health treatment in a primary care clinic. J Am Board Fam Pract. 2005; 18:87-96.

4. Herinckx HA, Kinney RF, Clarke GN, Paulson RI. Assertive community treatment versus usual care in engaging and retaining clients with severe mental illness. Psychiatr Serv. 1997;48:1297-306.

5. Rossi A, Amaddeo F, Bisoffi G, Ruggeri M. Dropping out of care: inappropriate terminations of contact with communitybased psychiatric services. Br J Psychiatry. 2002;181:331-8.

6. Simmonds S, Coid J, Joseph P, Marriott S, Tyrer P. Community mental health team management in severe mental illness: a systematic review. Br J Psychiatry. 2001;178:497-502.

7. Matas M, Staley D, Griffim W. A profile of the noncompliant patient: a thirty-month review of outpatient psychiatry referrals. Gen Hosp Psychiatry. 1992;14:124-30.

8. Melo AP, Guimarães MD. Fatores associados ao abandono do tratamento psiquiátrico em um centro de referência em saúde mental em Belo Horizonte. Rev Bras Psiquiatr. 2005;27:113-8.

9. Grunebaum M, Luber $\mathrm{P}$, Callaham M, Leon AC, Olfson M, Portera L. Predictors of missed appointments for psychiatric consultations in a primary care clinic. Psychiatr Serv. 1996;47:848-52.

10. Ribeiro MS, Poço JL. Motivos referidos para abandono de tratamento em um sistema público de atenção à saúde mental. Rev APS. 2006;9:136-45.

11. Percudani M, Belloni G, Contini A, Barbui C. Monitoring community psychiatric services in Italy: differences between patients who leave care and those who stay in treatment. $\mathrm{Br}$ J Psychiatry. 2002;180:254-9.

12. Young AS, Grusky O, Jordan D, Belin TR. Routine outcome monitoring in a public mental health system: the impact of patients who leave care. Psychiatr Serv. 2000;5:85-91.
13. Dobscha SK, Delucchi K, Young ML. Adherence with referrals for outpatient follow-up from a VA psychiatric emergency room. Community Ment Health J. 1999;35:451-8.

14. Ribeiro MS, Alves MJ, Silva PM, Vieira EM. Comparison of mental health assistance in primary care settings with or without Family Health Program team. Rev Psiquiatr Rio Gd Sul. 2009;1:40-50.

15. Ribeiro MS, Heckert U. Universidade e o cuidado à saúde: o "caso" do Serviço de Psiquiatria e Psicologia Médica do HUUFJF. Rev Saude Dist Fed. 2005;16:35-47.

16. Ribeiro MS, editor. Protocolos de conduta do Sistema Municipal de Saúde Mental de Juiz de Fora. Juiz de Fora: Sistema Único de Saúde; 2000.

17. Ribeiro MS, organizador. Ferramentas para descomplicar a atenção básica em saúde mental. Juiz de Fora: Universidade Federal de Juiz de Fora; 2007.

18. Bower P, Gilbody S. Managing common mental health disorders in primary care: conceptual models and evidence base. BMJ. 2005;330:839-42.

19. Organização Mundial da Saúde. Classificação de transtornos mentais e de comportamento da CID-10. Porto Alegre: Artes Médicas; 1993.

20. Wang J. Mental health treatment dropout and its correlates in a general population sample. Med Care. 2007;45:224-9.

21. Amaral MA. [Mental health care in health centers: study of the efficacy of the care given]. Rev Saude Publica. 1997;31:288-95.

22. Hauck S, Kruel L, Sordi A, Sbardellotto G, Cervieri A, Moschetti $L$, et al. Factors related to early dropout in psychoanalytic psychotherapy. Rev Psiquiatr Rio Gd Sul. 2007;29:265-73.

23. Ribeiro MS, Alves MJ, Silva PM, Vieira EM. Concordância diagnóstica entre profissionais dos níveis primário e secundário na atenção à saúde mental. Rev APS. 2008; 11:126-35.

24.Lucchese $R$, Oliveira AG, Conciani ME, Marcon SR. Saúde mental no Programa Saúde da Família: caminhos e impasses de uma trajetória necessária. Cad Saude Publica. 2009;25:2033-42.

\section{Correspondence}

Prof. Dr. Mário Sérgio Ribeiro

Rua Severino Meireles, 325/902

36025-040 - Juiz de Fora, MG - Brazil

E-mail: mariosribeiro@acessa.com 